\section{Effects of Vacuum Packaging on Enzymatic Browning and Ethylene Response Factor $(E R F)$ Gene Expression of Fresh-cut Lotus Root}

\author{
Ting Min, En-chao Liu, and Jun Xie \\ College of Food Science \& Engineering, Wuhan Polytechnic University, \\ Wuhan 430023, P.R. China
}

\author{
Yang Yi \\ College of Food Science \& Engineering, Wuhan Polytechnic University, \\ Wuhan 430023, P.R. China; and Hubei Collaborative Innovation Center for \\ Processing of Agricultural Products, Wuhan 430023, P.R. China
}

\section{Li-mei Wang and You-wei Ai}

College of Food Science \& Engineering, Wuhan Polytechnic University, Wuhan 430023, P.R. China

\section{Hong-xun Wang ${ }^{1}$ \\ College of Food Science \& Engineering, Wuhan Polytechnic University, Wuhan 430023, P.R. China; and Hubei Collaborative Innovation Center for Processing of Agricultural Products, Wuhan 430023, P.R. China}

Additional index words. Nelumbo nucifera, browning, PAL, PPO, POD, ERF

\begin{abstract}
Ethylene response factor $(E R F)$ genes have been involved in responses to biotic and abiotic stress, including hypoxia and anaerobic stress. Vacuum packaging (a typical anaerobic stress) is an effective storage method used to delay browning of fresh-cut lotus root (Nelumbo nucifera). In model plants, $E R F$ genes have been identified as responsive to hypoxia. Whether $E R F$ is associated with browning of vacuum-packaged lotus root has not been studied. The effects of vacuum packaging on browning, phenolic content, the enzyme activity of phenylalanine ammonia lyase (PAL), polyphenol oxidase (PPO), and peroxidase (POD), and $P P O, P A L, P O D$, and $E R F$ genes expression in fresh-cut lotus root were studied. Downregulation of $N n P A L 1, N n P P O A$, and $N n P O D 2 / 3$ attributable to vacuum packaging coincided with increased related enzyme activities and the degree of browning of fresh-cut lotus root. The expression patterns of $\mathrm{NnERF4/5}$ were consistent with the changes in $N n P A L 1, N n P P O A$, and $N n P O D 2 / 3$ gene expression. It has been proposed that $N n E R F 4 / 5$ could have be important regulators of fresh-cut lotus root browning, and that the relationships of $N n E R F 4 / 5$ and $N n P A L 1, N n P P O A$, and $N n P O D 2 / 3$ should to be studied further.
\end{abstract}

Lotus root is an important aquatic vegetable and export vegetable in China. There are abundant nutrients and high nutritional value, mainly including starch, sugar, protein, fat, and lecithin in lotus root (SolivaFortuny and Martıìn-Belloso, 2003). Because it is easy to cut, lotus root is more suitable for processing into fresh-cut products (Du et al., 2009). Fresh-cut lotus root is a fast and convenient food, and its processing procedure includes grading, finishing, cleaning, cutting, rest, preservation, and packaging.

Received for publication 5 Nov. 2018. Accepted for publication 1 Dec. 2018.

This research was supported by the National Key Research and Development Program of China (no. 2016YFD0400103) and Research Institute of Wuhan Polytechnic University (2018J02).

1Corresponding author. E-mail: 1471885254@qq. com.
However, during processing and storage, fresh-cut lotus root is highly susceptible to deterioration, which directly affects its quality and shelf life. The main reason for the decline in quality of fresh-cut products has been enzymatic browning (Eissa et al., 2006; Pma, 2006; Son et al., 2015).

At present, the methods for controlling the browning of lotus root mainly include chemical treatment (Kwon and Baek, 2014; Lu et al., 2007), modified atmosphere (MA) packaging (Cheng et al., 2015), vacuum packaging (Son et al., 2015; Xing et al., 2012), heat treatment (Tsouvaltzis et al., 2011), and low-temperature storage (Min et al., 2017). Among these, vacuum packaging is a natural preservation method that can greatly enhance the shelf life and overall quality of fresh produce (Mcdonald and Sun, 2000). Phenylalanine ammonia lyase (PAL), polyphenol oxidase (PPO), and peroxidase (POD) are involved in the enzymatic browning of many fruits and vegetables (Banerjee et al., 2015; Cheng et al., 2015; Ji-Lian et al., 2016; Zhou et al., 2003). However, vacuum packaging can delay the browning of fresh-cut lotus roots, and samples that have been vacuumpackaged have exhibited lower total phenol contents and PPO activity as well as lower degrees of browning than samples that have been air-packaged (Son et al., 2015; Xing et al., 2012). Our previous research reported that $N n P A L 1, N n P P O A$, and NnPOD1-6 are the most important candidate genes involved in the browning of fresh-cut lotus root ('E Lian 6') during storage at different temperatures (Min et al., 2017). However, the effect of vacuum packaging on $P A L$, $P P O$, and $P O D$ genes have not been reported for fresh-cut lotus root.

Ethylene response factor $(E R F)$ genes have been characterized in numerous plants in which they are involved in responses to biotic and abiotic stress, including hypoxia stress, cold stress, and heat stress (Licausi et al., 2013; Min et al., 2012; Müller and Munné-Bosch, 2015; Phukan et al., 2017). It has been reported that hypoxia-responsive $E R F$ genes (HRE) have been characterized in Arabidopsis, with HRE1 and HRE2 having partially redundant roles in increasing lowoxygen tolerance (Hinz et al., 2010; Licausi et al., 2010; Yang et al., 2011). Two hypoxiaresponsive $E R F$ genes (DkERF9 and DkERF10) were involved in regulating persimmon deastringency by separately regulating $D k P D C 2$ and $D k A D H 1$ promoters (Min et al., 2012). Although the anaerobic environment produced by vacuum packaging or low temperatures is a type of unfavorable stress for plants, it has a remarkable effect on delaying browning of fresh-cut lotus root. In our previous study, we explored the role of $E R F$ in delaying lotus root browning at low temperatures, and we found that $N n E R F 3 / 4 / 5$ could be important regulators of browning of fresh-cut lotus root during storage at low temperatures. Whether ERF is associated with the browning of lotus roots that are vacuum-packaged requires further study.

Ethylene can enhance rachis browning in Vitis vinifera and accelerate the browning of fresh-cut Colocasia esculenta during storage (Li and Zhang, 2015; Tan and Zeng, 2014). It is well known that $E R F$ plays an important role in the realization of ethylene function (Nakano et al., 2006), suggesting that $E R F$ may be involved in plant browning. $E R F$ generally realizes functions by combining downstream genes. It has been reported that $D c E R F 1$ and DcERF2 may commit to the upregulation of $D C P A L 3$ promoter activity in anthocyanin-synthesizing carrot cells (Kimura et al., 2008). GbERF1 regulated lignin biosynthesis-related enzymes, including PAL, to improve resistance to Verticillium dahliae (Guo et al., 2016). A study of aphid resistance indicated that downregulation of $E R F$ gene expression was consistent with the lower POD and PPO activities due to high $\mathrm{CO}_{2}$ (Guo et al., 2013). ThCRF1 (a subfamily member of the $E R F$ transcription factor from Tamarix hispida) has improved 
tolerance to salt-shock-induced stress by improving SOD and POD activities (Qin et al., 2017). This suggests that $E R F$ may be involved in the synthesis of phenolic precursors through the transcriptional regulation of $P A L$ in plants or the transcriptional regulation of $P P O$ and $P O D$ involved in plant stress responses. Therefore, it is necessary to further study how $E R F$ participates in the browning of lotus root that has been vacuumpackaged.

In this study, the effects of vacuum packaging on browning, total phenol, the enzyme activity of PPO, PAL, and POD, and the expression patterns of $P P O, P A L$, $P O D$, and $E R F$ were analyzed. Some $P P O$, $P A L, P O D$, and NnERF genes were positively correlated with lotus root browning, and the possible roles of these and other $N n E R F$ genes are discussed.

\section{Materials and Methods}

\section{Sample preparation}

Lotus root ('E lian 5') was purchased from the commercial agricultural wholesale market (Four Seasons) in 2016; then, it was immediately shipped to the laboratory. It had a uniform size and color, and there were no defects or mechanical damage. Before samples were processed, the lotus roots were stored at $4{ }^{\circ} \mathrm{C}$ for $24 \mathrm{~h}$. Then, lotus root was rinsed with clean water to remove the soil and peeled. Next, using a stainless-steel knife, it was cut into 5-mm-thick slices along the cross-section. The slices were transferred to clean water, sterilized by ozone for $5 \mathrm{~min}$, and dried with clean filter paper. Some of the cymbals were vacuum-packed, and the other part was packaged with atmospheric pressure. Finally, samples were transferred to a refrigerator $\left(4^{\circ} \mathrm{C}\right)$.

\section{Physicochemical parameters}

Physicochemical parameters of fresh-cut lotus root slices, including the degree of browning and total phenolic content, were measured according to a previously published method (Min et al., 2017). All treatments were performed with three biological replicates.

Determination of the degree of browning. The degree of browning (Min et al., 2017) was determined using modified versions of methods referred to in the previous literature. At $4{ }^{\circ} \mathrm{C}$, $30 \mathrm{~mL}$ of distilled water was mixed with $3.0 \mathrm{~g}$ of sliced lotus root tissue. It was homogenized and then centrifuged for $5 \mathrm{~min}$ at $10,000 \mathrm{~g}_{\mathrm{n}}$. Next, the supernatant in the centrifuge tube was collected. After incubating for $5 \mathrm{~min}$ in a $25^{\circ} \mathrm{C}$ water bath, the absorbance was measured at $410 \mathrm{~nm}$ using a spectrophotometer. The browning degree was expressed as $\mathrm{A}_{410} \times 10$.

Determination of the total phenolic content. The total phenolic content was measured according to the Folin-Ciocalteu method (Liu et al., 2018; Min et al., 2017). Three grams of sliced fresh lotus root tissue samples were homogenized with $30 \mathrm{~mL}$ of $60 \%$ ethanol and centrifuged at $10,000 g_{n}$ for $5 \mathrm{~min}$. The supernatant $(10 \mathrm{~mL})$ was diluted with $40 \mathrm{~mL}$ of $60 \%$ ethanol for the next measurement. The sample solution $(0.125$ $\mathrm{mL}$ ) was mixed with $0.625 \mathrm{~mL}$ of distilled water; then, $0.125 \mathrm{~mL}$ of Folin phenol reagent was added. After thorough mixing (oscillation for $30 \mathrm{~s}$ ), the mixture was permitted to stand at room temperature for $3 \mathrm{~min}$; then, $1.25 \mathrm{~mL}$ of $7 \% \mathrm{Na}_{2} \mathrm{CO}_{3}$ and $1.0 \mathrm{~mL}$ of distilled water were added. Finally, it was allowed to stand in a water bath at $25{ }^{\circ} \mathrm{C}$ for $90 \mathrm{~min}$. Then, the absorbance was measured using a spectrophotometer at $760 \mathrm{~nm}$. The standard curve of gallic acid was used to determine the total phenolic content. The result was expressed as milligrams of gallic acid equivalents per kilogram of fresh weight $\left(\mathrm{mg} \cdot \mathrm{kg}^{-1}\right)$.

Determination of PAL, PPO, and POD enzyme activities. PAL activity was extracted and determined using a phenylalanine ammonia lyase activity assay kit (Nan Jing Jiancheng Bioengineering Institute, Nanjing, China) (Min et al., 2017). There were four reagents in the kit (reagents $1-4) ; 0.1 \mathrm{~g}$ of the sliced tissue was added to $1 \mathrm{~mL}$ of reagent 1 under ice bath conditions for homogenization. Then, the sample was centrifuged at $10,000 g_{n}$ for $10 \mathrm{~min}$ at $4{ }^{\circ} \mathrm{C}$, and the supernatant was collected as a crude PAL extract. The reaction mixture consisted of 20 $\mu \mathrm{L}$ of crude PAL extract, $780 \mu \mathrm{L}$ of reagent 2 (blank group $800 \mu \mathrm{L}$ ), and $200 \mu \mathrm{L}$ of reagent 3. Afterward, the mixture was incubated at $30{ }^{\circ} \mathrm{C}$ for $30 \mathrm{~min}$, and $40 \mu \mathrm{L}$ of reagent 4 was added. Finally, it was allowed to stand at room temperature for $10 \mathrm{~min}$, and the absorbance of the sample was measured at $290 \mathrm{~nm}$. One unit of PAL activity was defined as the amount of enzyme that catalyzed when the change in absorbance was 0.1 per gram of fresh sample at $290 \mathrm{~nm}$.

Extraction and determination of PPO activity were based on the literature (Min et al., 2017). Under ice bath conditions, $3.0 \mathrm{~g}$ of sliced lotus root was homogenized in 50 $\mathrm{mL}$ of phosphate-buffered saline (PBS) $(0.05$ $\left.\mathrm{mol} \cdot \mathrm{L}^{-1} ; \mathrm{pH}=7.0\right)$. Then, the solution was centrifuged at $3820 \mathrm{~g}_{\mathrm{n}}$ for $15 \mathrm{~min}$, and the supernatant was collected as a crude PPO extract. Next, we prepared a reaction mixture consisting of $1.0 \mathrm{~mL}$ of $0.1 \mathrm{~mol} \cdot \mathrm{L}^{-1}$ catechol and $1.5 \mathrm{~mL}$ of PBS. The mixture was incubated at $35{ }^{\circ} \mathrm{C}$ for $5 \mathrm{~min}$; then, $1.0 \mathrm{~mL}$ of crude PPO was added to the mixture. Afterward, the absorbances of the mixture were measured at $420 \mathrm{~nm}$ over time. After the enzyme solution was added, the absorbance value was measured every $10 \mathrm{~s}$ during the first $1 \mathrm{~min}$, and then every $30 \mathrm{~s}$ until $3.5 \mathrm{~min}$. The absorbance value (OD) was measured over time. Finally, the enzyme activity was calculated based on the slope (OD/t) of the straight segment. An enzyme activity unit was described as the amount of enzyme leading to a change in absorbance of 0.001 per min.

Extraction and determination of POD activity refer to related articles with some modifications (Abohatem et al., 2011). Under ice bath conditions, the extraction buffer (5.0 $\mathrm{mL} ; 0.2 \mathrm{~mol} \cdot \mathrm{L}^{-1}$ ) was added to $5.0 \mathrm{~g}$ of fresh chopped lotus root for homogenization (the extraction buffer contained $1 \mathrm{~mm}$ polyethyl- ene glycol-6000, 4\% polyvinyl pyrrolidone, and $1 \%$ Triton $\mathrm{X}-100$ ). Then, the homogenized sample was centrifuged at $15,290 g_{n}$ for $30 \mathrm{~min}$ at $4{ }^{\circ} \mathrm{C}$. Afterward, the supernatant was collected to determine the POD activity. Finally, $3.0 \mathrm{~mL}$ of $25 \mathrm{~m} \mathrm{~mol} \cdot \mathrm{L}^{-1}$ guaiacol, 0.5 $\mathrm{mL}$ of enzyme solution (blank of extraction buffer), and $0.2 \mathrm{~mL}$ of $5 \mathrm{~mol} \cdot \mathrm{L}^{-1}$ dissolved hydrogen peroxide were added to the supernatant. The absorbance change in the mixture was recorded every $10 \mathrm{~s}$ at $470 \mathrm{~nm}$. One unit of enzyme activity was defined as the amount of enzyme leading to a change in absorbance of 0.01 per min.

$R N A$ extraction and $c D N A$ synthesis. Total RNA content was prepared according to previous methods (Min et al., 2015). DNA traces of contaminated genomes in total RNA were cleared using TURBO Dnase (Ambion). Then, $1.0 \mathrm{ug}$ of DNA-free RNA was used for cDNA synthesis using the iScript cDNA Synthesis Kit (Bio-Rad) protocol. At each sampling point, RNA extraction was repeated using three samples.

Expression analysis of the ERF gene. Oligonucleotide primers for polymerase chain reaction (PCR) analyses were described previously (Min et al., 2015). According to previous literature, gene expression studies used the Ssofast EvaGreen Supermix kit (Bio-Rad) and CFX96 fluorescent PCR detection system for real-time PCR (Yang et al., 2018). Furthermore, 5.0 $\mu \mathrm{L} 2 \times$ Ssofast EvaGreen Supermix, $0.5 \mu \mathrm{L}$ upstream primer (10 $\mu \mathrm{mol}), 0.5 \mu \mathrm{L}$ downstream primer $(10 \mu \mathrm{mol})$, $1.0 \mu \mathrm{L}$ diluted cDNA, and $3.0 \mu \mathrm{L} \mathrm{H}_{2} \mathrm{O}$ were used.

The PCR procedure was as follows: $95^{\circ} \mathrm{C}$ for $3 \mathrm{~min}$; $95^{\circ} \mathrm{C}$ for $10 \mathrm{~s}$ for 45 cycles; and $60{ }^{\circ} \mathrm{C}$ for $30 \mathrm{~s}$. Then, the melting curve analysis was completed. The relative expression of each gene was calibrated using the sample from the day 0 control group. In addition, the relative expression levels of the genes were referenced to the lotus root Actin gene, and each gene was set as a negative control with no template. Each gene expression experiment was performed in triplicate.

\section{Data analysis}

Figures were drawn using Origin 8.0 software. Statistical analyses of differences was analyzed using least significant difference.

\section{Results and Discussion}

\section{Browning degree}

The browning degree was the main indicator of the browning of fruits and vegetables (Baxter, 2010). In this study, different packaging conditions (vacuum packaging and atmospheric packaging at $4{ }^{\circ} \mathrm{C}$ ) were used to store fresh-cut lotus root slices. The results showed that the browning degree during storage was significantly different between the two packaging methods (Fig. 1). Compared with atmospheric packaging, the browning degree of fresh-cut lotus roots in vacuum packaging was markedly delayed (between 0.215 and 0.285 ), and the browning degree of roots in atmospheric packaging 
changed greatly (between 0.215 and 0.610 ). Therefore, vacuum packaging could effectively delay the browning process of fresh-cut lotus root; these results were similar to the results of a previous study (Shan et al., 2013).

\section{Total phenolic content}

As shown in Fig. 2, the total phenolic content of fresh-cut lotus roots was significantly different in various packaging methods. The total phenolic content of the vacuum-packaged sample at $4{ }^{\circ} \mathrm{C}$ decreased and then increased, but the content was not significantly different from beginning to end ( $96.891 \mathrm{mg} / \mathrm{kg}$ on day 0 to $108.981 \mathrm{mg} / \mathrm{kg}$ on day 35). The total phenolic content of atmospheric pressure-packaged samples increased greatly from $96.891 \mathrm{mg} / \mathrm{kg}$ on day 0 to $159.252 \mathrm{mg} / \mathrm{kg}$ on day 35. Moreover, the results showed that storage in vacuum packaging delayed the increase in the total phenolic content in fresh-cut slices; these results were consistent with those of a previous study (Min et al., 2017).

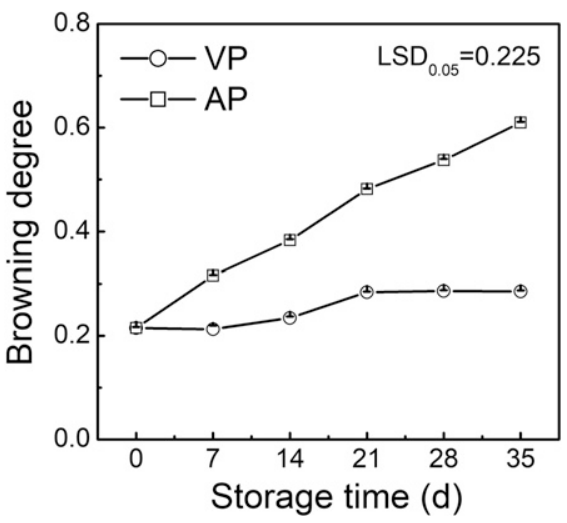

Fig. 1. Effects of two different types of packaging on the degree of browning of fresh-cut lotus root ('E Lian 5'). Fresh-cut lotus root was separately stored in vacuum packaging (VP) (circles) and atmospheric packaging (AP) (squares) at $4{ }^{\circ} \mathrm{C}$. Error bars represent SEs from three biological replicates.

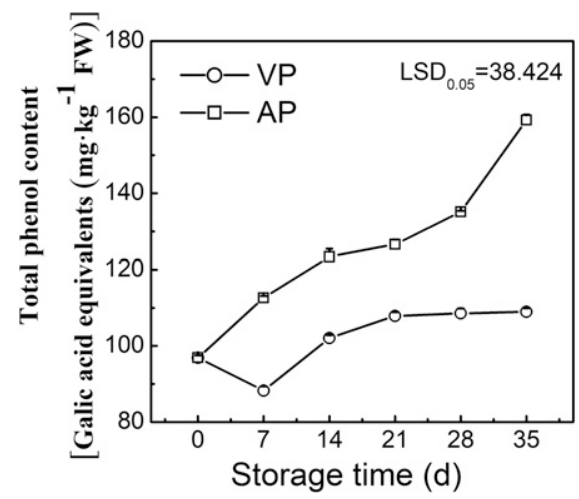

Fig. 2. Effects of two different types of packaging on the total phenol content of fresh-cut lotus root ('E Lian 5'). Fresh-cut lotus root was separately stored in vacuum packaging (VP) (circles) and atmospheric packaging (AP) (squares) at $4{ }^{\circ} \mathrm{C}$. Error bars represent SEs from three biological replicates.

\section{PAL, PPO, and POD activities}

PAL, PPO, and POD enzyme activities in the two different types of packages were significantly different (Fig. 3). PAL activity in the two different packaging samples was increased, and there was no significant difference during the early stage of storage (the first 2 weeks) (Fig. 3A). However, PAL enzyme activity increased rapidly, ranging from $8.708 \mathrm{U} / \mathrm{g}$ on day 0 to $12.225 \mathrm{U} / \mathrm{g}$ on day 35 in the control group; however, vacuumpackaged samples showed no significant change in PAL activity. The PPO activity in the vacuum packaging was lower than that in the atmospheric pressure packaging during the whole storage period. The initial PPO value ranged from 0.396 to $0.604 \mathrm{U} / \mathrm{g}$ in the vacuum group and $1.178 \mathrm{U} / \mathrm{g}$ in the atmospheric pressure group on day 35 (Fig. 3B). This indicated that PPO enzyme activity was very sensitive in vacuum packaging, and that the PPO enzyme is the key enzyme for the browning of fruits and vegetables; these results were consistent with those of a previous study (Min et al., 2017). Similar to PAL, the most significant difference in activity between packaging methods became apparent after day 14: POD activity in the vacuum group samples increased from $0.528 \mathrm{U} / \mathrm{g}$ on day 14 to $0.604 \mathrm{U} / \mathrm{g}$ on day 35 , whereas activity in the atmospheric group increased from $0.904 \mathrm{U} / \mathrm{g}$ to $1.178 \mathrm{U} / \mathrm{g}$ during the same time period (Fig. 3C). Finally, the PAL, PPO, and POD enzymatic activities in the vacuum packaging were lower than those in the atmospheric pressure packaging, which indicated that the vacuum conditions could effectively inhibit enzyme activity and, thus, inhibit enzymatic browning (Xing et al., 2012).

During this experiment, the changes in PAL, PPO, and POD activities under different packaging conditions were studied, and the changes were consistent with the browning of fresh-cut lotus root during storage; these results were consistent with those of previous reports (Banerjee et al., 2015; Cheng et al., 2015).

\section{Gene expression of NnPAL, NnPPO, and NnPOD}

Two different types of packaging had different effects on the two NnPAL genes (Fig. 4). NnPAL1 expression in atmospheric packaging increased gradually during the whole storage period, reaching a peak on day 28. NnPAL1 was continuously repressed by vacuum packaging, and the transcript abundance was decreased by more than 60 fold on day 28. NnPAL2 mRNA accumulation increased in vacuum packaging, and the levels were relatively lower than those for NnPAL1. It was suggested that the expression PAL enzyme activity and browning degree, and that NnPAL1 was most likely to be involved in the synthesis of phenolic compounds in lotus root browning, which was supported by our previous work (Min et al., 2017).

$N n P P O A$ transcripts were increased in atmospheric pressure packaging, whereas it remained constant in vacuum packaging, inhibited NnPPOA expression. Similar to $N n P P O A, N n P P O C$ transcripts were increased of $N n P A L 1$ mRNA paralleled the changes in which suggested that vacuum packaging

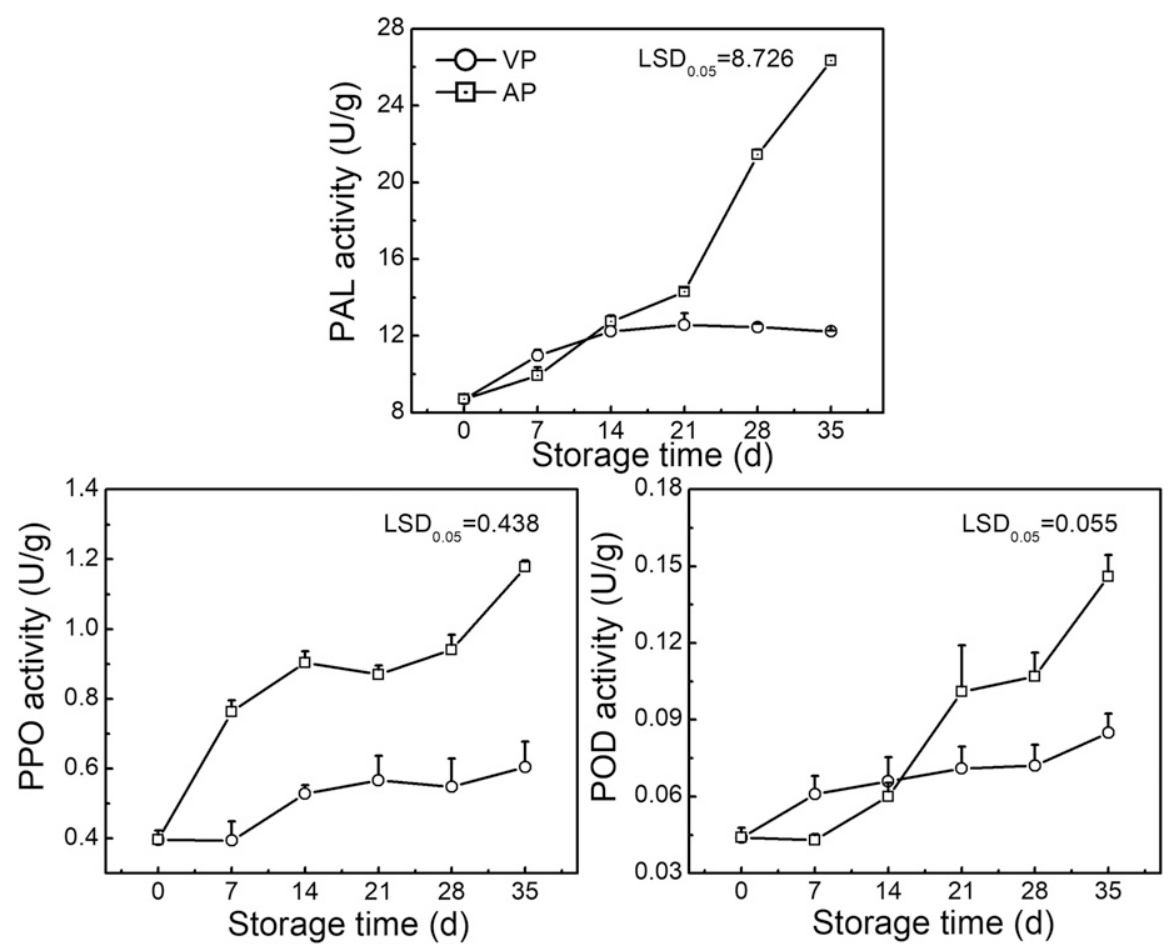

Fig. 3. Effects of two different types of packaging on phenylalanine ammonia lyase (PAL) (A), polyphenol oxidase (PPO) (B), and peroxidase (POD) activity (C) ('E Lian 5'). Fresh-cut lotus root was separately stored in vacuum packaging (VP) (circles) and atmospheric packaging (AP) (squares) at $4{ }^{\circ} \mathrm{C}$. Error bars represent SES from three biological replicates. 
in atmospheric pressure packaging, whereas it decreased on day 1 and remained constant in vacuum packaging, but with much lower levels (Fig. 5). It was suggested that $N n P P O A$ mRNA changes were consistent with the PPO enzyme activity and browning degree. Furthermore, $N n P P O A$ was most likely involved in lotus root browning. Similar results have been reported by other studies (Min et al., 2017).

In the $N n P O D$ gene family, $N n P O D 2 / 3$ mRNA were significantly decreased in vacuum packaging compared with atmospheric packaging during the whole storage time (Fig. 6). This phenomenon indicated that

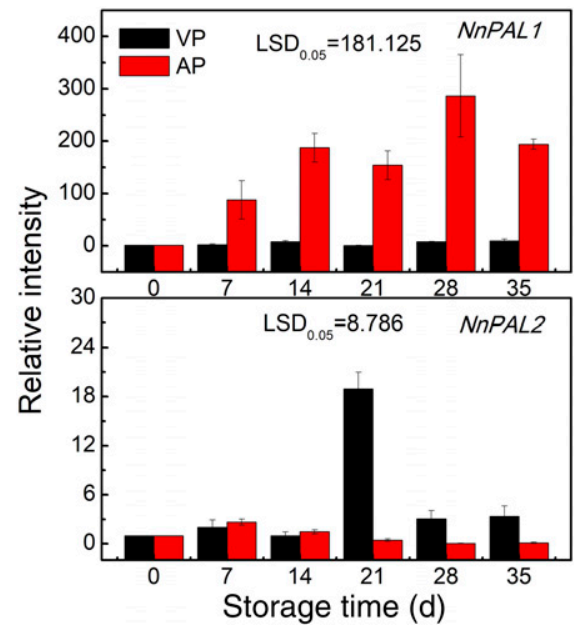

Fig. 4. Messenger RNA (mRNA) from phenylalanine ammonia lyase $(P A L)$ genes in response to different temperature treatments. Fresh-cut lotus root was separately stored in vacuum packaging (VP) (black) and atmospheric packing (AP) (red) at $4{ }^{\circ} \mathrm{C}$. The day 0 sample values were set at 1. Error bars represent SEs from three biological replicates.

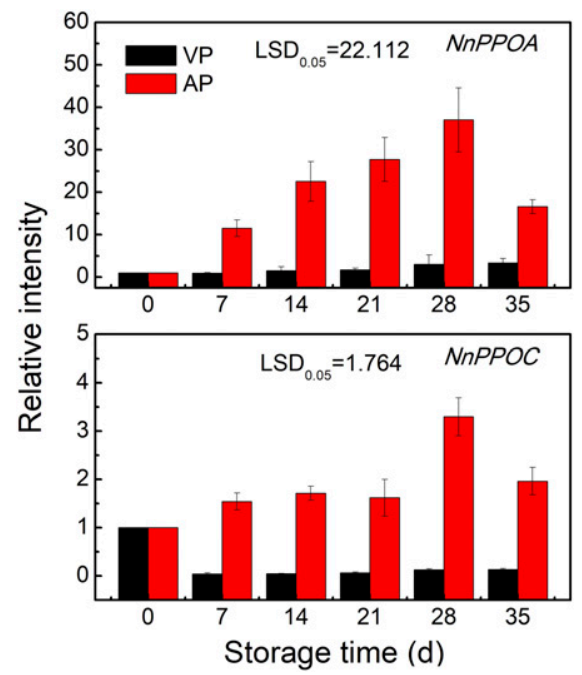

Fig. 5. Messenger RNA (mRNA) from polyphenol oxidase $(P P O)$ genes in response to different temperature treatments. Fresh-cut lotus root was separately stored in vacuum packaging (VP) (black) and atmospheric packing (AP) (red) at $4{ }^{\circ} \mathrm{C}$. Error bars represent SEs from three biological replicates. vacuum packaging inhibited the expression of these two genes, which was consistent with the changes in POD enzyme activity and browning degree. NnPOD1/5 were inhibited during early storage and upregulated during late storage in vacuum packaging. $\mathrm{NnPOD4} /$ 6 were induced by vacuum packaging during the whole storage period. Nevertheless, there was no significant difference in $N n P O D 7$ expression between the two packaging methods. It was suggested that the expression patterns of $N n P O D 2 / 3$ were consistent with the changes in POD enzyme activity and browning degree; therefore, they may be key genes involved in lotus root browning.

Our previous work found that downregulation of $N n P A L 1, N n P P O A$, and NnPOD2-4 was consistent with the decreased browning of fresh lotus roots at low temperatures for two different varieties ('E lian 6' and ' $\mathrm{E}$ lian 5') (Min et al., 2017). Changes in NnPALl, NnPPOA, and NnPOD2/3 expressions occurred in parallel with changes in PAL, PPO, and POD enzyme activities and the browning degree in vacuum and atmospheric packaging. Based on the present results and our previous report, $N n P A L 1, N n P P O A$, and $N n P O D 2 / 3$ are the key genes affecting the browning of fresh-cut lotus root; however, further functional analyses should be performed to confirm these results.

\section{ERF gene expression}

Seven $E R F$ genes were isolated during our previous study. These $E R F$ genes showed diverse expression patterns (Fig. 7). NnERF2 was induced by vacuum packaging during the early stage; however, it was induced by atmospheric pressure packaging during the later stage. There was no obvious difference in the expression of $N n E R F 3$ in the two types of packaging. NnERF4 expression increased and then decreased during storage in the two types of packaging, but it was always lower in vacuum packaging than in atmospheric pressure packaging during the early and middle storage periods (days 7, 14, and 21), although the expression was relatively low. NnERF5 mRNA increased gradually during the whole storage period, peaking on day 35 , but NnERF5 was significantly upregulated in vacuum packaging compared with that in atmospheric packaging. $N n E R F 1 / 6 / 7$ were significantly induced by vacuum packaging, and the transcript abundance was increased by more than 800-, 400-, 700-fold, respectively.

NnERF4/5 expressions were significantly suppressed by vacuum packaging, which was consistent with NnPAL1, NnPPOA, and $N n P O D 2 / 3$ changes and browning. This indicated that in lotus root, the decreased expressions of NnERF4/5 were concurrent with decreases in browning; however, the specific relationship between $E R F$ and browning is unclear and should be studied further. In our previous study, we found that $N n E R F 3 / 4 / 5$ were continuously downregulated by low temperatures and were associated with the browning of fresh-cut lotus roots under low-temperature conditions. Therefore, it was proposed that $N n E R F 3 / 4 / 5$ could be important regulators of fresh-cut
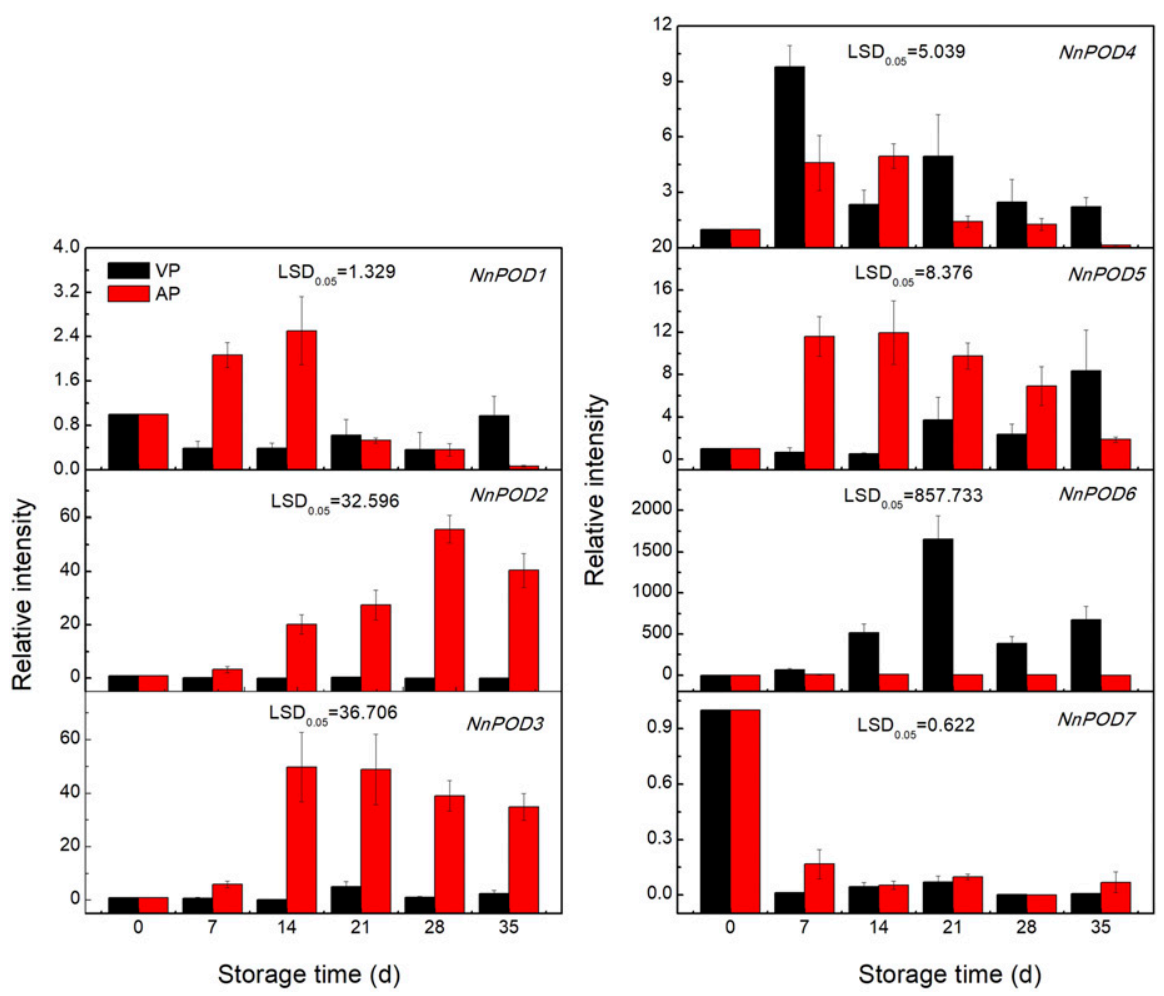

Fig. 6. Messenger RNA (mRNA) from peroxidase $(P O D)$ genes in response to different temperature treatments. Fresh-cut lotus root was separately stored in vacuum packaging (VP) (black) and atmospheric packing (AP) (red) at $4{ }^{\circ} \mathrm{C}$. Error bars represent SEs from three biological replicates. 

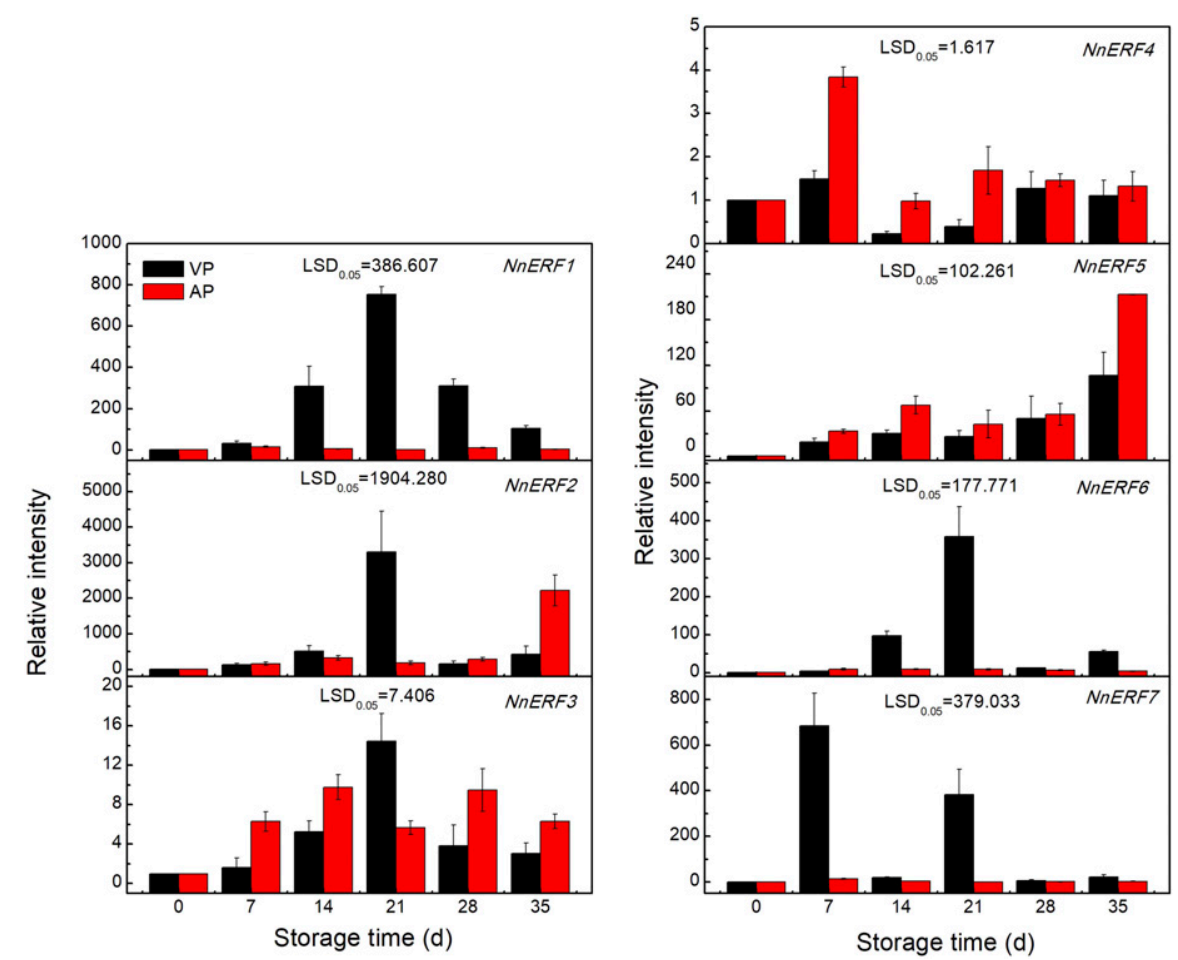

Fig. 7. Messenger RNA (mRNA) from ethylene response factor $(E R F)$ genes in response to different temperature treatments. Fresh-cut lotus root was separately stored in vacuum packaging (VP) (black) and atmospheric packing (AP) (red) at $4{ }^{\circ} \mathrm{C}$. Error bars represent sEs from three biological replicates.

lotus root browning. We further studied the effects of vacuum packaging on browning and $E R F$ gene expression in lotus root. $N n E R F 4 / 5$ were highly correlated with the browning process of lotus root, which further supported the previous findings. Therefore, NnERF4/5 were proposed to be important regulators of fresh-cut lotus root browning. Moreover, because of the significantly different expression levels of ERF4 and ERF5 during storage, and because of the differences in the response to vacuum packaging compared with ERF4, it seemed that NnERF5 was more positively correlated with browning, and that ERF4/5 might have different roles in lotus root browning. ERF4 mainly participated in lotus root browning during early storage, whereas ERF5 functioned during the whole storage period. The relationships of NnERF4/5 and NnPAL1, NnPPOA, and $N n P O D 2 / 3$ during lotus root browning should be the subject of further research. NnERF1/6/7 were significantly increased during vacuum storage, which indicated that they are more sensitive to hypoxia stress (vacuum storage). The processing of freshcut fruits and vegetables promotes physiological and biochemical changes in the product (Toivonen and Brummell, 2008). These changes may cause significant decreases in color, texture, and flavor. Fresh-cut peppers in vacuum packaging had more noticeable ethanol and acetaldehyde contents, which are essential to the flavor of fresh-cut products (González-Aguilar et al., 2004). Therefore, $N n E R F 1 / 6 / 7$ may be related to the loss of quality of fruits and vegetables, especially the loss of flavor. Similar studies involving two hypoxia-responsive $E R F$ (DkERF9 and $D k E R F 10)$ genes showed acetaldehyde and ethanol synthesis in persimmon were separately regulated by $D k P D C$ and $D k A D H$ promoters (Min et al., 2014).

\section{Conclusions}

Browning and PAL, PPO, and POD enzyme activity and gene expression results of this study showed that vacuum packaging effectively delayed lotus root browning. The downregulation of $N n P A L 1, N n P P O A$, and $N n P O D 2 / 3$ in vacuum packaging coincided with the increased related enzyme activities and the browning degree of fresh-cut lotus root. Furthermore, the expression patterns of $N n E R F 4 / 5$ were consistent with the changes in NnPAL1, NnPPOA, and NnPOD2/3 gene expressions. It has been proposed that NnERF4/5 could be important regulators of fresh-cut lotus root browning.

\section{Literature Cited}

Abohatem, M., J. Zouine, and I.E. Hadrami. 2011. Low concentrations of BAP and high rate of subcultures improve the establishment and multiplication of somatic embryos in date palm suspension cultures by limiting oxidative browning associated with high levels of total phenols and peroxidase activities. Scientia Hort. 130: 344-348.

Banerjee, A., P. Suprasanna, S. Variyar, and A. Sharma. 2015. Gamma irradiation inhibits wound induced browning in shredded cabbage. Food Chem. 173:38-44.

Baxter, J.H. 2010. Free Amino Acid Stability in Reducing Sugar Systems. J. Food Sci. 60:405-408.
Cheng, Y., L. Liu, G. Zhao, C. Shen, H. Yan, J. Guan, and K. Yang. 2015. The effects of modified atmosphere packaging on core browning and the expression patterns of PPO and PAL genes in 'Yali' pears during cold storage. LWT - Food Sci Techn. 60:12431248.

Du, J., Y. Fu, and N. Wang. 2009. Effects of aqueous chlorine dioxide treatment on browning of fresh-cut lotus root. LWT - Food Sci Techn. 42:654-659.

Eissa, H.A., H.H.M. Fadel, G.E. Ibrahim, I.M. Hassan, and A.A. Elrashid. 2006. Thiol containing compounds as controlling agents of enzymatic browning in some apple products. Food Res. Intl. 39:855-863.

González-Aguilar, G.A., J.F. Ayala-Zavala, S. Ruiz-Cruz, E. Acedo-Félix, and M.E. DíazCinco. 2004. Effect of temperature and modified atmosphere packaging on overall quality of fresh-cut bell peppers. LWT - Food Sci Techn. 37:817-826.

Guo, H., Y. Sun, Y. Li, X. Liu, W. Zhang, and F. Ge. 2013. Elevated $\mathrm{CO}_{2}$ decreases the response of the ethylene signaling pathway in Medicago truncatula and increases the abundance of the pea aphid. New Phytol. 201:279-291.

Guo, W., L. Jin, Y. Miao, X. He, Q. Hu, K. Guo, L. Zhu, and X. Zhang. 2016. An ethylene response-related factor, GbERF1-like, from Gossypium barbadense improves resistance to Verticillium dahliae via activating lignin synthesis. Plant Mol. Biol. 91:305-318.

Hinz, M., I.W. Wilson, J. Yang, K. Buerstenbinder, D. Llewellyn, E.S. Dennis, M. Sauter, and R. Dolferus. 2010. Arabidopsis RAP2.2: An ethylene response transcription factor that is important for hypoxia survival. Plant Physiol. 153:757-772.

Ji-Lian, Z., H. Lan-Ying, H. Kang-Di, W. Jun, Y. Feng, and Z. Hua. 2016. Hydrogen Sulfide Alleviates Senescence of Fresh-cut Apple by Regulating Antioxidant Defense System and Senescence-related Gene Expression. HortScience 51:152-158.

Kimura, S., Y. Chikagawa, M. Kato, K. Maeda, and Y. Ozeki. 2008. Upregulation of the promoter activity of the carrot (Daucus carota) phenylalanine ammonia-lyase gene (DcPAL3) is caused by new members of the transcriptional regulatory proteins, DcERF1 and DcERF2, which bind to the GCC-box homolog and act as an activa. J. Plant Res. 121:499-508.

Kwon, S.Y. and H.H. Baek. 2014. Effects of temperature, $\mathrm{pH}$, organic acids, and sulfites on tagatose browning in solutions during processing and storage. Food Sci. Biotechnol. 23:677-684.

Li, T. and M. Zhang. 2015. Effects of modified atmosphere package (MAP) with a silicon gum film window on the quality of stored green asparagus (Asparagus officinalis L) spears. Lebensm. Wiss. Technol. 60:1046-1053.

Licausi, F., M. Ohme-Takagi, and P. Perata. 2013. APETALA2/Ethylene Responsive Factor (AP2/ERF) transcription factors: Mediators of stress responses and developmental programs. New Phytol. 199:639-649.

Licausi, F., J.T. Van Dongen, B. Giuntoli, G. Novi, A. Santaniello, P. Geigenberger, and P. Perata. 2010. HRE1 and HRE2, two hypoxiainducible ethylene response factors, affect anaerobic responses in Arabidopsis thaliana. Plant Journal for Cell \& Molecular Biology 62:302-315.

Liu, S., E. Liu, B. Zhu, B. Chai, R. Liu, Q. Gao, and B. Zhang. 2018. Impact of maceration time on colour-related phenolics, sensory characteristics 
and volatile composition of mulberry wine. J I Brewing. 124:45-56.

Lu, S., Y. Luo, E. Turner, and H. Feng. 2007. Efficacy of sodium chlorite as an inhibitor of enzymatic browning in apple slices. Food Chem. 104:824-829.

Müller, M. and S. Munné-Bosch. 2015. Ethylene Response Factors: A Key Regulatory Hub in Hormone and Stress Signaling. Plant Physiol. 169:32-41.

Mcdonald, K. and D.W. Sun. 2000. Vacuum cooling technology for the food processing industry: A review. J Food Eng. 45:55-65.

Min, T., F. Fang, H. Ge, Y.N. Shi, Z.R. Luo, Y.C. Yao, D. Grierson, X.R. Yin, and K.S. Chen. 2014. Two novel anoxia-induced ethylene response factors that interact with promoters of deastringency-related genes from persimmon. PLoS One 9:97043.

Min, T., M.M. Wang, H.X. Wang, X.F. Liu, F. Fang, D. Grierson, X.R. Yin, and K.S. Chen. 2015. Isolation and expression of NAC genes during persimmon fruit postharvest astringency removal. Intl. J. Mol. Sci. 16:1894-1906.

Min, T., J. Xie, M.L. Zheng, Y. Yi, W.F. Hou, L.M. Wang, Y.W. Ai, and H.X. Wang. 2017. The effect of different temperatures on browning incidence and phenol compound metabolism in fresh-cut lotus (Nelumbo nucifera G.) root. Postharvest Biol. Technol. 123:69-76.

Min, T., X.R. Yin, Y.N. Shi, Z.R. Luo, Y.C. Yao, D. Grierson, I.B. Ferguson, and K.S. Chen. 2012. Ethylene-responsive transcription factors interact with promoters of $\mathrm{ADH}$ and $\mathrm{PDC}$ involved in persimmon (Diospyros kaki) fruit de-astringency. J. Expt. Bot. 63:6393-6405.

Nakano, T., K. Suzuki, T. Fujimura, and H. Shinshi. 2006. Genome-wide analysis of the ERF gene family in Arabidopsis and rice. Plant Physiol. 140:411.

Phukan, U.J., G.S. Jeena, V. Tripathi, and R.K. Shukla. 2017. Regulation of Apetala2/Ethylene response factors in plants. Front. Plant Sci. 8:150.

Pma, T. 2006. Fresh-cut apples: Challenges and opportunities for multi-disciplinary research. Can. J. Plant Sci. 86:1361-1368.

Qin, L., L. Wang, Y. Guo, Y. Li, H. Ümüt, and Y. Wang. 2017. An ERF transcription factor from Tamarix hispida, ThCRF1, can adjust osmotic potential and reactive oxygen species scavenging capability to improve salt tolerance. Plant Sci. 265:154.

Shan, L.I., Y. Zhu, F.U. Da-Qi, B.Z. Zhu, R. Hao, and Y.B. Luo. 2013. Effect of chitosan coating combined with oxygen-free packaging on enzymatic browning during cold storage of young lotus rhizomes. Food Sci. 17:243-251.

Soliva-Fortuny, R.C. and O. Martı̀n-Belloso. 2003. New advances in extending the shelflife of fresh-cut fruits: A review. Trends Food Sci. Technol. 14:341-353.

Son, J., J.E. Hyun, J.W. Lee, S.Y. Lee, and B. Moon. 2015. Combined application of antibrowning, heat treatment and modifiedatmosphere packaging to extend the shelf life of fresh-cut lotus root. J. Food Sci. 80:C1178C1187.

Tan, Y.T. and K.F. Zeng. 2014. Effects of combined treatment with ascorbic acid, cysteine and $\mathrm{CaCl} 2$ on browning of fresh-cut taro. Food Science 35:231-235.

Toivonen, P.M.A. and D.A. Brummell. 2008. Biochemical bases of appearance and texture changes in fresh-cut fruit and vegetables. Postharvest Biol. Technol. 48:1-14.

Tsouvaltzis, P., A. Deltsidis, and J.K. Brecht. 2011. Hot water treatment and pre-processing storage reduce browning development in freshcut potato slices. HortScience 46:1282-1286.

Xing, Y., X. Li, Q. Xu, J. Yun, and Y. Lu. 2012. Extending the shelf life of fresh-cut lotus root with antibrowning agents, cinnamon oil fumigation and moderate vacuum packaging. J. Food Process Eng. 35:505-521.

Yang, C.Y., F.C. Hsu, J.P. Li, N.N. Wang, and M.C. Shih. 2011. The AP2/ERF transcription factor AtERF73/HRE1 modulates ethylene responses during hypoxia in Arabidopsis. Plant Physiol. 156:202-212.

Yang, R., J. Liu, Z. Lin, W. Sun, Z. Wu, H. Hu, and Y. Zhang. 2018. ERF transcription factors involved in salt response in tomato. Plant Growth Regulat. 84:573-582.

Zhou, Y., J.M. Dahler, U. Sjr, and W. Rbh. 2003. Enzymes associated with blackheart development in pineapple fruit. Food Chem. 80:565572 . 